\title{
Functional properties of glycoside synthesized using polyphenolic extract of Moringa oleifera catalyzed through transglycosylation reaction
}

\author{
Sohaib Nazir, Joko Sulistyo* \\ Faculty of Food Science and Nutrition, Universiti Malaysia Sabah, Kota Kinabalu, Malaysia.
}

\section{ARTICLE INFO \\ Received on: 10/12/2017 \\ Accepted on: 04/08/2018 \\ Available online: 08/05/2018}

\section{Key words:}

Moringa oleifera, transglycosylation, polyphenol glycoside, antioxidant.

\begin{abstract}
The present study was designed to investigate gallic acid-4-O- $\beta$-glucopyranoside (GAGP) in normal and alloxaninduced diabetic rats by a single dose administration of alloxan $(150 \mathrm{mg} / \mathrm{kg}$, i.p.). Blood glucose levels measured were significantly $(p<0.05)$ increasing in all diabetic rats as compared with normal control rats. Three different dosages of GAGP $(100,200$, and $400 \mathrm{mg} / \mathrm{kg}$, body weight) showed significantly decreasing $(p<0.05)$ blood glucose levels of the diabetic rats $(<3 \%)$ as compared with untreated diabetic group $(>66 \%)$. All the hyperglycemic groups which were treated with various dosages of GAGP recorded lower biochemical parameters of blood serum as compared with untreated diabetic group. A significant reduction in catalase activity $(<40 \%-60 \%)$ of the diabetic groups was observed as compared with control group, while the diabetic groups showed elevation as compared with untreated diabetic group and catalase activity was quite near to normal rats. Glutathione levels of the diabetic groups were reduced $(<2 \%-3 \%)$ but diabetic treated groups with different dosage showed improvement near to normal rats. In diabetic rat tissue, significant elevation $(>45 \%)$ in lipid peroxidation was observed as compared with normal rats. In contrast, treatment with GAGP restores back near towards normal level $(>5 \%-15 \%)$.
\end{abstract}

\section{INTRODUCTION}

Moringa oleifera Lam. Syn. (Moringaceae) is well known for their pharmacological actions and is used for the traditional treatment of diabetes mellitus (Babu and Chaudhuri, 2005). Its leaves, fruits, and stem bark have been scientifically examined for their use in hypercholesterolemia (Ghasi et al., 2000; Mehta et al., 2003). Fruits and stem bark have been reported to have anti-diabetic action (Kar et al., 2003). It was found to contain many essential nutrients, for instance, vitamins, minerals, amino acids, beta-carotene, antioxidants, and anti-inflammatory nutrients (Kasolo et al., 2010). Due to the presence of several sorts of phenolics compound, it was able to extend the period of food containing fats regarding with its antioxidant activity (Dillard and

\section{"Corresponding Author}

Joko Sulistyo, Faculty of Food Science and Nutrition, Universiti Malaysia Sabah, Kota Kinabalu, Malaysia.E-mail: jsmsulthan@gmail.com
German, 2000; Siddhuraju and Becker, 2003). However, there are no reports on hypoglycemic and anti-diabetic actions of its leaves.

Nevertheless, polyphenols are of restricted use because they are easily spoiled, degraded in an aqueous solution followingon in rapid browning. Nevertheless, although the constituents might have such beneficial properties, however, their use is restricted due to their low stability and solubility and they are easily degraded in an aqueous solution following in rapid browning reaction (Nayak et al., 2015). For that reason, their antioxidant properties were influenced or reduced. It has been found that a number of physical properties of the polyphenols were enhanced through enzymatic transglycosylation reaction (Sulistyo et al., 2001; 2014). Glycosylation of polyphenols into glycosides has a number of advantages in contrast to chemical synthesis, for example, lowcost production and its enzyme, which is derived from microbial culture as a source of enzyme with transglycosylation capacity, can also be produced for the purpose of synthesis of several bioactive compounds due to its easiness and simplicity procedure. 
On the other side, the chemical synthesis of glycosides is not only complex and complicated but also expensive. Moreover, it is not as simple as enzymatic reaction since it generates a complex mixture of products with $\alpha$ - and $\beta$-configuration. Enzymatic transglycosylation permits insoluble and less stable organic bioactive compounds to be changed into the resultant soluble and more stable compounds during suitable single-step glycosylation (Shimoda et al., 2006). The clinical importance of polyphenol glycosides is one of the pharmacological interests (Satoh et al., 2001).

The aim of the study was to investigate a purified and identified gallic acid-4-O- $\beta$-D-glucopyranoside (GAGP) as enzymatically synthesized polyphenol glycoside that had been obtained by application of Cyclodextrin glucano transferase (CGTase) derived from Trichoderma viride in the presence of polyphenolic extract of $M$. oleifera leaves, dealing with its capability as antioxidative, hypolipidemic agent, and antidiabetic agent using animal model experiment.

\section{MATERIALS AND METHODS}

\section{Extraction of polyphenols}

Extraction of polyphenolic compounds was done by following the method of Charoensin (2014) with slight modification. The leaves of $M$. oleifera (1.0 kg dried base weight) which had been purchased from a local market were dried in hot air oven at $50^{\circ} \mathrm{C}$ for 72 hours and ground to powder (approximately $600 \mathrm{~g}$ ) and preserved overnight at $4^{\circ} \mathrm{C}$ until extraction. Fifteen grams of the powder was extracted with $350 \mathrm{ml}$ of methanol and the liquid extract was filtered through Whatman No. 1 filter paper. Solvent was removed by using rotary evaporator and the extract was freeze-dried to obtain crude polyphenol (approximately $30 \mathrm{mg})$.

\section{Isolation and purification of synthesized glycosides}

A reaction mixture $(200 \mathrm{ml})$ containing prepared polyphenolic constituents of $M$. oleifera used as substrate-acceptor $(2.5 \%, \mathrm{w} / \mathrm{v})$ and a commercial Nona wheat flour $(5.0 \%, \mathrm{w} / \mathrm{v})$ as substrate-donor were incubated with $T$. viride CGTase at $40^{\circ} \mathrm{C}$ for 24 hours. The reaction mixture was extracted with diethyl ether to remove residual unreacted polyphenolic constituents and separated. The aqueous phase was concentrated and the crude mixture was then subjected to column chromatography for separation which was eluted with a gradient solvent of methanol in $1 \%$ formic acid $(\mathrm{v} / \mathrm{v})$. Fraction solutions resulted by flushing the column that is exhibited single spots on thin layer chromatography plate where their retention factor values were parallel to the spot of arbutin as an authentic reference of commercial polyphenol glycoside were then collected and concentrated (Hashmi et al., 2014).

\section{HPLC analysis and structure identification by NMR spectroscopy}

The purified transfer products (TPs) were also analyzed by using high performance liquid chromatography (HPLC). The HPLC/ Ultra violet-visible (UV-VIS) system was comprised of Agilent HPLC system provided with a pump, an automatic injector, an UV-VIS detector, and a degasser. Separations were carried out using Apollo C18 reverse-phase column at room temperature. Acetonitrile (A) and $0.1 \%$ aqueous $\mathrm{H}_{3} \mathrm{PO}_{4}(\mathrm{~B})$ were used as a mobile phase with a gradient elution of $24 \%(\mathrm{~A})$ at $0-12$ minutes, $24-50 \%$ (A) at $12-22$ minutes, $50 \%-24 \%$ (A) at $22-40$ minutes, and $24 \%$ (A) at 40-50 minutes. The separation was monitored through absorbance at $254 \mathrm{~nm}$ at a flow rate of $0.5 \mathrm{ml} /$ minute (Chiang et al., 2012). The ${ }^{1} \mathrm{H}$-nuclear magnetic resonance (NMR), ${ }^{13}$ C-NMR spectra were measured using a Varian XL-400 spectrometer in dimethyl sulfoxide (DMSO) solution. The purified transfer products were furthermore identified by using proton and carbon-13 nuclear magnetic resonance $\left({ }^{1} \mathrm{H}-\mathrm{NMR}\right.$ and $\left.{ }^{13} \mathrm{C}-\mathrm{NMR}\right)$ spectroscopy using a Varian XL-400 spectrometer in DMSO solution (Shimoda and Hamada, 2010)

\section{Animal Model Experiment}

Male Sprague-Dawley rats weighing about 100-200 g, obtained from Faculty of Food Science and Nutrition, Universiti Malaysia Sabah, were used. The animals were housed in colony plastic cages at an ambient temperature of $25^{\circ} \mathrm{C}-27^{\circ} \mathrm{C}$ under a 12 hour light/dark cycle and free admittance to standard rat diet and tap water. The rats were allowed to adapt to the laboratory environment for 1 week before starting the experiment. All the experimental procedures were performed according to the ethical guidelines for the use and care of laboratory animals.

\section{Induction of diabetes}

Diabetes mellitus was induced by a single intraperitoneal injection of alloxan monohydrate freshly prepared at a dose of $150 \mathrm{mg} / \mathrm{kg}$, body weight (BW). It was observed that 4 hours after the alloxan injection, tap water was changed with a 5\% glucose solution for 24 hours (Prince et al., 2004). Also, 1 week after the alloxan injection, the blood glucose level of the overnight fasted animals was checked by the use of glucometer. The animals that displayed glucose levels higher than $200 \mathrm{mg} / \mathrm{dl}$ were considered as diabetic rats and furthermore, they were included in the study (Manickam and Periyasamy, 2013).

\section{Assessment of catalase activity}

Catalase activity was determined by following the method of Pari and Latha (2004). The percent catalase inhibition was determined by monitoring decrease in absorbance at 620 $\mathrm{nm}$. The pancreas was homogenized and centrifuged at 5,000 rpm in $0.01 \mathrm{M}$ phosphate buffer $(\mathrm{pH} 7.0)$. The reaction mixture comprised of $0.4 \mathrm{ml}$ of $\mathrm{H}_{2} \mathrm{O}_{2}(0.2 \mathrm{M}), 1 \mathrm{ml}$ of $0.01 \mathrm{M}$ phosphate buffer having $\mathrm{pH} 7.0$, and $0.1 \mathrm{ml}$ of pancreas homogenate $(10 \%$ $\mathrm{w} / \mathrm{v})$. The reaction was stopped by the addition of $2 \mathrm{ml}$ reagent (5\% $\mathrm{K}_{2} \mathrm{Cr}_{2} \mathrm{O}_{7}$ prepared in glacial acetic acid). The changes in the absorbance were observed at $620 \mathrm{~nm}$. Percent inhibition was analyzed as follows; \% catalase inhibition $=[$ (normal activity inhibited activity) $/($ normal activity $)] \times 100$.

\section{Assessment of reduced glutathione (GSH) activity}

Modified method of Oyedemi et al. (2010) was used to determine the reduced GSH. $1.0 \mathrm{ml}$ supernatant of pancreas homogenate was treated with $0.5 \mathrm{ml}$ of Ellman's reagent $(19.8 \mathrm{mg}$ of 5,5 '-dithiobisnitro benzoic acid in $100 \mathrm{ml}$ of $0.1 \%$ sodium nitrate) and $3 \mathrm{ml}$ of phosphate buffer $(0.2 \mathrm{M}, \mathrm{pH} 8.0)$. The absorbance was recorded at $412 \mathrm{~nm}$ and percent inhibition of reduced GSH was calculated as $\% \mathrm{GSH}$ inhibition $=\left(A_{0}-A_{1}\right) / A_{0} \times 100$, where 


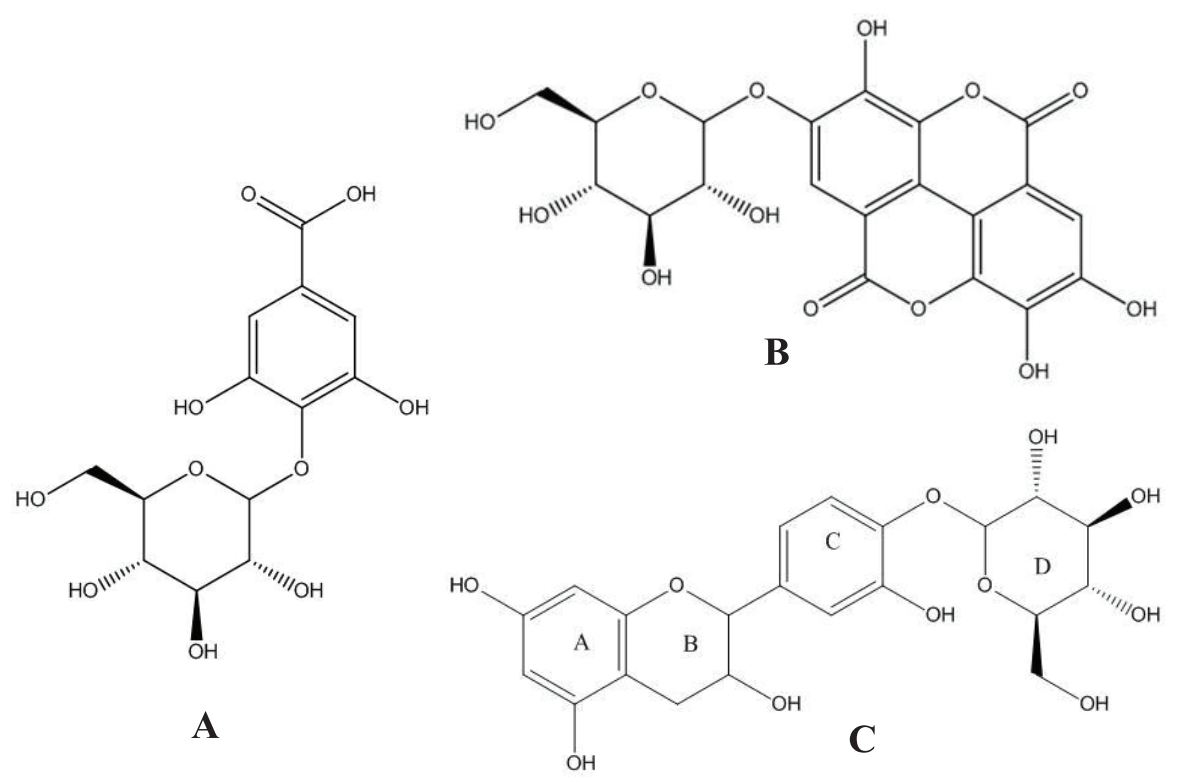

Figure 1. Chemical structure of GAGP (A); EAGP (B); and catechin-4'-O- $\beta$-D-glucopyranoside (C).

$A_{0}$ is the absorbance of the control and $A_{1}$ is the absorbance of the sample extract.

\section{Assessment of lipid peroxidation (LPO)}

LPO was determined colorimetrically by thiobarbituric acid (TBA) reactive substances. Briefly, $0.1 \mathrm{ml}$ of pancreas homogenate $(10 \% \mathrm{w} / \mathrm{v})$ was treated with $2 \mathrm{ml}$ of $(1: 1: 1, \mathrm{v} / \mathrm{v} / \mathrm{v})$ TBA-trichloroacetic acid (TCA)- $\mathrm{HCl}$ reagent $(0.37 \%$ TBA, $15 \%$ TCA, and $0.25 \mathrm{~N} \mathrm{HCl}$ ). All the tubes were kept in a water bath at $100^{\circ} \mathrm{C}$ for half an hour and cooled. The amount of malondialdehyde (MDA) produced in all samples was calculated by evaluating the absorbance of the supernatant at $535 \mathrm{~nm}$ against blank (Oyedemi et al., 2010). Percent inhibition was computed using the following equation; \% Inhibition $=\left(A_{0}-A_{1}\right) A_{0} \times 100$, where $A_{0}$ is the absorbance of the control and $A_{1}$ is the absorbance of the sample extract.

\section{Determination of biochemical parameters}

Biochemical parameters including total cholesterol, triglycerides, low-density lipoprotein, high-density lipoprotein, creatinine, urea, and alkaline phosphatase levels in blood plasma were measured using special kits (Abbott Laboratories, USA) which utilized the colorimetric method in an auto-analyzer (Cherbal et al., 2017). Twenty-five rats were randomly divided into five groups (five rats in each group); Group-1, normal untreated rats were given distilled water; Group-2, diabetic untreated rats were given distilled water; Group-3, diabetic rats were given GAGP at a dose of $100 \mathrm{mg} / \mathrm{kg}$, BW; Group-4, diabetic rats were given GAGP at a dose of $200 \mathrm{mg} / \mathrm{kg}, \mathrm{BW}$; and Group-5, diabetic rats were given GAGP at a dose of 400 $\mathrm{mg} / \mathrm{kg}, \mathrm{BW}$. Distilled water and drug preparations were served orally by gastric intubation to the rats of respective groups using force feeding needle, once daily for 4 weeks. All five groups of rats were sacrificed on the last day of treatment after overnight fasting and the blood sample of each animal was collected from cardiac punctures after cervical dislocation before their heartbeats stop. The blood glucose levels were determined at different day intervals by using glucometer and blood was collected from the tail vein. The blood samples were collected in separated BD Vacutainer ${ }^{\circledR}$ Blood Collection Tubes. The blood samples were centrifuged at $1,375 \times \mathrm{g}$ for 20 minutes and the serum was separated.

\section{RESULTS AND DISCUSSION}

\section{Purification and structural identification of transglycosylation products}

Enzyme-catalyzed synthesis of polyphenolic glycosides, as transglycosylation products of crude $M$. oleifera leaves extract, were purified using octa dodecyl sulphate column chromatography followed by structural identification identified on the basis of spectroscopic techniques. According to the analysis using ${ }^{13} \mathrm{C}$-NMR and ${ }^{1} \mathrm{H}-\mathrm{NMR}$ spectra, the isolated compounds were identified as GAGP, ellagic acid-4-O- $\beta$-glucopyranoside (EAGP), and catechin-4'-O-glucopyranoside (CGP), respectively (Fig. 1). These chemical structures corresponded to the composition of $M$. oleifera leaves extract which contains approximately $10 \%-11 \%$ gallic acid, 5\%-6\% ellagic acid, and 2\%-3\% catechin (Nazir et al., 2018). The ${ }^{1}$ hydrogen (proton) NMR (HNMR) and ${ }^{13}$ Carbon NMR (CNMR) spectrum of compound GAGP revealed the presence of glycosidic bond in gallic acid glucopyranoside. The broad singlet at $\delta_{H} 7.03$ corresponds to the two protons of the aromatic ring. The ${ }^{13} \mathrm{CNMR}$ showed one signal resonating at $\delta_{c} 114.96$, which could be attributed to $\mathrm{C}-4$. The shifting of this signal to the higher field confirms the glycosidic linkage at C-4. The presence of a signal at $\delta_{c} 123.6$ corresponds to $\mathrm{C}-2$ and $\mathrm{C}-6$ while the signal at 138.9 corresponds to $\mathrm{C}-3$ and $\mathrm{C}-5$ reveals that the aromatic ring of GAGP has a plane of symmetry. More signals are provided in Table 1. GAGP: infrared in $\mathrm{K}$ (potassium) bromide powder $\left(v_{\max } / \mathrm{cm}^{-1}\right)$ : ${ }^{1} \mathrm{H}-\mathrm{NMR}\left(500 \mathrm{MHz}\right.$; CD $\left.\mathrm{OD}-d_{4} / \mathrm{ppm}\right) \delta: 7.03$ (1H, bs, H-3), 7.03 $(1 \mathrm{H}, \mathrm{bs}, \mathrm{H}-7), 4.35$ (1H, d, J $\left.7.8 \mathrm{~Hz}, \mathrm{H}-1^{\prime}\right), 4.26(1 \mathrm{H}, \mathrm{dd}, J$ 8.3, $\left.7.8 \mathrm{~Hz}, \mathrm{H}-2^{\prime}\right), 3.26$ (1H, dd, $J$ 9.3, $\left.8.3 \mathrm{~Hz}, \mathrm{H}-3^{\prime}\right), 4.33$ (1H, dd, $J$ 
Table 1. ${ }^{1} \mathrm{H}-\mathrm{NMR}$ and ${ }^{13} \mathrm{C}-\mathrm{NMR}$ chemical shift of synthesized transglycosylation products.

\begin{tabular}{|c|c|c|c|c|c|c|}
\hline \multirow[b]{2}{*}{ C } & \multicolumn{2}{|l|}{ TP-1 } & \multicolumn{2}{|c|}{ TP-2 } & \multicolumn{2}{|l|}{ TP-3 } \\
\hline & $\delta^{1} \mathrm{H}, J(\mathrm{~Hz})$ & $\delta^{13} \mathrm{C}$ & $\delta^{1} \mathbf{H}, J(H z)$ & $\delta^{13} \mathrm{C}$ & $\delta^{1} \mathrm{H}, J(\mathrm{~Hz})$ & $\delta^{13} \mathrm{C}$ \\
\hline 1 & & & & 126.4 & $6.84(\mathrm{~d}, J=1.93)$ & 130.2 \\
\hline 2 & $7.03(\mathrm{bs})$ & 123.6 & & 140.6 & & 108.6 \\
\hline 3 & & 138.9 & & 132.7 & & 144.8 \\
\hline 4 & & 144.9 & $7.80(\mathrm{~s})$ & 146.2 & $7.24(\mathrm{~d}, J=8.43)$ & 147.96 \\
\hline 5 & & 138.9 & & 101.6 & & 116.9 \\
\hline 6 & $7.03(\mathrm{bs})$ & 123.6 & & 120.2 & $7.01(\mathrm{dd}, J=2.54,8.69)$ & 119.9 \\
\hline 7 & & & & 161.2 & & \\
\hline 1 , & $4.35(\mathrm{~d}, 7.8)$ & 101.9 & & 111.4 & $4.60(\mathrm{~d}, J=1.93)$ & 82.4 \\
\hline '' & $4.26(\mathrm{dd}, 8.3,7.8)$ & 73.8 & & 158.7 & $3.99(\mathrm{~m})$ & 67.7 \\
\hline $3^{\prime}$ & $3.26(\mathrm{dd}, 9.3,8.3)$ & 78.4 & & 160.9 & $2.52-2.94(\mathrm{~m})$ & 29.6 \\
\hline 4' & $4.33(\mathrm{dd}, 9.3,9.3)$ & 71.1 & $6.39(\mathrm{~s})$ & 140.4 & & 156.4 \\
\hline 5 , & $3.37(\mathrm{~m})$ & 79.9 & & 120.5 & $5.84(\mathrm{~d}, J=2.06)$ & 96.5 \\
\hline 6 & & & & 108.5 & & 157.5 \\
\hline 7 & & & & 161.2 & $5.93(\mathrm{~d}, J=2.06)$ & 95.9 \\
\hline $1 "$ & & & $4.99(\mathrm{~d}, 7.1)$ & 101.7 & $4.05(\mathrm{~m})$ & 100.7 \\
\hline $2 "$ & & & $4.08(\mathrm{~m})$ & 74.9 & $3.48(\mathrm{~m})$ & 73.9 \\
\hline 3" & & & $4.30(\mathrm{~m})$ & 77.4 & $3.38(\mathrm{~m})$ & 80.4 \\
\hline $4 "$ & & & $4.19(\mathrm{~m})$ & 70.1 & $4.13(\mathrm{~m})$ & 71.3 \\
\hline $5 "$ & & & $4.06(\mathrm{~s})$ & 78.2 & $3.40(\mathrm{~s})$ & 78.9 \\
\hline $6 "$ & $4.06(\mathrm{dd}, 11.3,5.6)$ & 63.9 & $4.18(\mathrm{~m})$ & 63.2 & $3.68(\mathrm{~m})$ & 64.2 \\
\hline $6 "$ & $4.37(\mathrm{bd}, 11.3)$ & & $4.33(\mathrm{~m})$ & & $3.89(\mathrm{~m})$ & \\
\hline
\end{tabular}

9.3, $9.3 \mathrm{~Hz}, \mathrm{H}-4$ '), 3.37 (1H, m, H-5'), 4.06 (1H, dd, J 11.3, 5.6 $\left.\mathrm{Hz}, \mathrm{H}-6{ }^{\prime} \alpha\right), 4.37$ (1H, bd, $\left.J 11.3 \mathrm{~Hz}, \mathrm{H}-6{ }^{\prime} \beta\right) .{ }^{13} \mathrm{C}-\mathrm{NMR}$ spectrum (125 MHz; DMSO- $\left.d_{6} / \mathrm{ppm}\right): 166.2(\mathrm{C}-1), 123.6$ (C-2), 108.8 (C-3), 144.96 (C-4), 138.9 (C-5), 144.9 (C-6), 108.8 (C-7), 101.9 (C-1'), 73.8 (C-2'), $78.4\left(\mathrm{C}-3^{\prime}\right), 71.1\left(\mathrm{C}-4^{\prime}\right), 79.9\left(\mathrm{C}-5^{\prime}\right), 63.9$ (C-6') (Fig. 1A). Functional properties of GAGP were determined through in vivo and in vitro experiments, i.e. antioxidative, hypolipidemic and antidiabetic agents.

The ${ }^{1} \mathrm{HNMR}$ and ${ }^{13} \mathrm{CNMR}$ spectrum of EAGP revealed the presence of glycosidic bond in EAGP. The broad singlet at $\delta_{H} 7.03$ corresponds to the two protons of the aromatic ring. The ${ }^{13} \mathrm{CNMR}$ showed one signal resonating at $\delta_{c} 114.96$, which could be attributed to $\mathrm{C}-4$. The shifting of this signal to the higher field confirms the glycosidic linkage at $\mathrm{C}-4$. The presence of a signal at $\delta c 123.6$ corresponds to $\mathrm{C}-2$ and $\mathrm{C}-6$ while the signal at 138.9 corresponds to $\mathrm{C}-3$ and $\mathrm{C}-5$ reveals that aromatic ring of EAGP has a plane of symmetry. More signals are provided in Table 1. EAGP: ${ }^{1} \mathrm{H}$ NMR spectrum $(500$ MHz; DMSO- $\left.d_{\sigma} / \mathrm{ppm}\right): \delta 7.80(1 \mathrm{H}, s, \mathrm{H}-5), \delta 6.39\left(1 \mathrm{H}, s, \mathrm{H}-5^{\prime}\right)$, $\delta 6.05\left(1 \mathrm{H}, m, \mathrm{H}-1^{\prime \prime}\right), \delta 4.08\left(1 \mathrm{H}, m, \mathrm{H}-2^{\prime \prime}\right), \delta 4.30(1 \mathrm{H}, m$, H-3"), $\delta 4.19\left(1 \mathrm{H}, m, \mathrm{H}-4^{\prime \prime}\right), \delta 4.06\left(1 \mathrm{H}, m, \mathrm{H}-5^{\prime \prime}\right), \delta 4.18(1 \mathrm{H}$, $m$ H-6" $\left.{ }_{\mathrm{a}}\right), \delta 4.33\left(1 \mathrm{H}, m \mathrm{H}-6{ }^{\prime \prime}\right) .{ }^{13} \mathrm{C}$ NMR spectrum $(125 \mathrm{MHz}$; DMSO- $\left.d_{6} / \mathrm{ppm}\right): \delta 126.4$ (C-1), 140.6 (C-2), 132.7 (C-3), 140.2 (C-4), 101.6 (C-5), 120.2 (C-6), 161.2 (C-7), $111.4\left(\mathrm{C}-1^{\prime}\right)$, $158.7\left(\mathrm{C}-2^{\prime}\right), 160.9\left(\mathrm{C}-3^{\prime}\right), 146.4\left(\mathrm{C}-4^{\prime}\right), 120.5\left(\mathrm{C}-5^{\prime}\right), 108.5(\mathrm{C}-$ 6'), $165.0\left(\mathrm{C}-7^{\prime}\right), 101.7\left(\mathrm{C}-1^{\prime \prime}\right), 74.9\left(\mathrm{C}-2^{\prime \prime}\right), 77.4$ (C-3"), 70.1 (C-4"), 78.2 (C-5"), 63.2 (C-6") (Fig. 1B).

The ${ }^{1} \mathrm{H}$ NMR spectrum of CGP revealed the presence of double doublet of $\mathrm{H}-6$ at $\delta_{H} 7.01$ of aromatic ring $\mathrm{C}$ whereas two doublets at $\delta_{\mathrm{H}} 6.84$ and 7.24 having a coupling constant of 1.93 and 8.43 could be attributed to $\mathrm{H}-2$ and $\mathrm{H}-5$, respectively. The ${ }^{13} \mathrm{CNMR}$ spectrum showed expected signals, which corresponds to all carbon present in the structure. The signal at $\delta_{c} 147.9$ was at higher filed assigned to a C-4 carbon atom of the aromatic ring, confirming the glycosidic linkage. Another signal at $\delta, 144.8$ was attributed to $\mathrm{C}-3$ as this carbon of aromatic ring $\mathrm{C}$ is attached to a hydroxyl group. The ${ }^{1} \mathrm{H}$ NMR spectrum of compound CGP revealed the presence of two characteristic singlets of H-5 at $\delta_{H} 7.80$ and H-5' at $\delta_{H} 6.39$. The doublet at $\delta_{H} 4.99$ having the coupling constant $(J=7.1 \mathrm{~Hz})$ was assigned to $\mathrm{H}-1$ " which confirms the presence of sugar moiety as $\beta-\mathrm{D}$-glucose. The ${ }^{13} \mathrm{CNMR}$ spectrum showed expected signals, which corresponds to all carbon present in the structure. The signal at $\delta \mathrm{c} 146.2$ could be assigned to $\mathrm{C}-4$. This higher field confirms the position of glycosidic linkage to the aglycone moiety. Catechin-4'-O- $\beta$-glucopyranoside: ${ }^{1} \mathrm{H}-\mathrm{NMR}$ $\left(500 \mathrm{MHz} ; \mathrm{CD}_{3} \mathrm{OD}-d_{4} / \mathrm{ppm}\right) \delta: 7.24(1 \mathrm{H}, d, \mathrm{H}-2), 6.84(1 \mathrm{H}, d$, $\mathrm{H}-5), 7.01(1 \mathrm{H}, d, \mathrm{H}-6), 4.60\left(1 \mathrm{H}, d, \mathrm{H}-1^{\prime}\right), 3.99\left(1 \mathrm{H}, \mathrm{dd}, \mathrm{H}-2^{\prime}\right)$, 2.52-2.94 (2H, $\left.m, \mathrm{H}-3^{\prime}\right), 5.84\left(1 \mathrm{H}, d, \mathrm{H}-5^{\prime}\right), 5.93$ (1H, $\left.d, \mathrm{H}-7^{\prime}\right) . \delta$ 4.05 (1H, $\left.m, \mathrm{H}-1^{\prime \prime}\right), \delta 3.48$ (1H, $\left.m, \mathrm{H}-2^{\prime \prime}\right), \delta 3.38$ (1H, $\left.m, \mathrm{H}-3^{\prime \prime}\right), \delta$ $4.13\left(1 \mathrm{H}, m, \mathrm{H}-4^{\prime \prime}\right), \delta 3.40$ (1H, $\left.m, \mathrm{H}-5^{\prime \prime}\right), \delta 3.68$ (1H, $\left.m \mathrm{H}-6^{\prime \prime}{ }_{\mathrm{a}}\right)$, $\delta 3.89\left(1 \mathrm{H}, m \mathrm{H}-6{ }^{\prime \prime}\right) \cdot{ }^{13} \mathrm{C}$ NMR spectrum $\left(125 \mathrm{MHz}\right.$; DMSO- $d_{\sigma} /$ ppm): 130.2 (C-1), 108.6 (C-2), 144.8 (C-3), 147.96 (C-4), 116.9 (C-5), 119.9 (C-6), $82.4\left(\mathrm{C}-1^{\prime}\right), 67.7$ (C-2'), 29.6 (C-3'), 156.4 (C4'), 96.5 (C-5'), 157.5 (C-6'), 95.9.0 (C-7'), 93.3 (C-8'), 100.7 (C1"), 73.9 (C-2"), 80.4 (C-3"), 71.3 (C-4"), 78.9 (C-5"), 64.2 (C-6") (Fig. 1C).

\section{Body weight}

As shown in Figure 2, this study demonstrated that all diabetes-induced groups had significantly lower BW as compared with the normal control group after the alloxan injection on day-4. The decrease in BW is reported as a marker for the development of diabetes since the $\mathrm{BW}$ in diabetic animals' decreases due to the impairment in insulin action in transforming glucose into glycogen and catabolism of fats. Beta cell destruction also causes unavailability of lipolysis. 


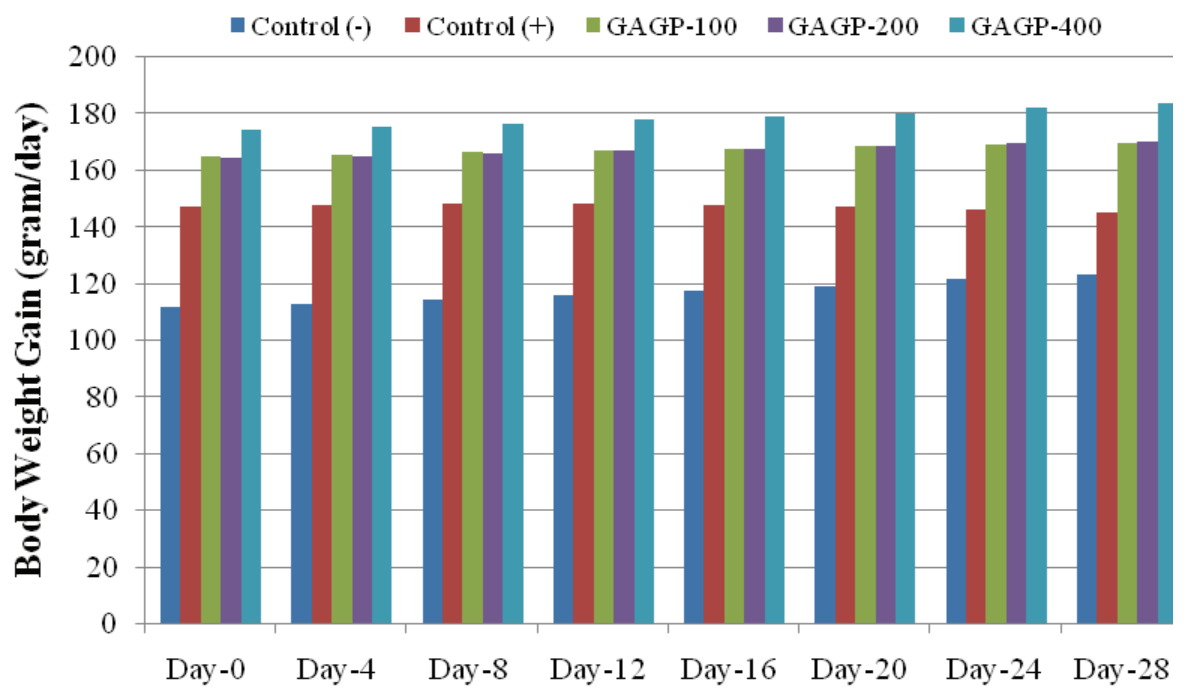

Body Weight Observation (day)

Figure 2. Effect of administration of GAGP on BW gain.

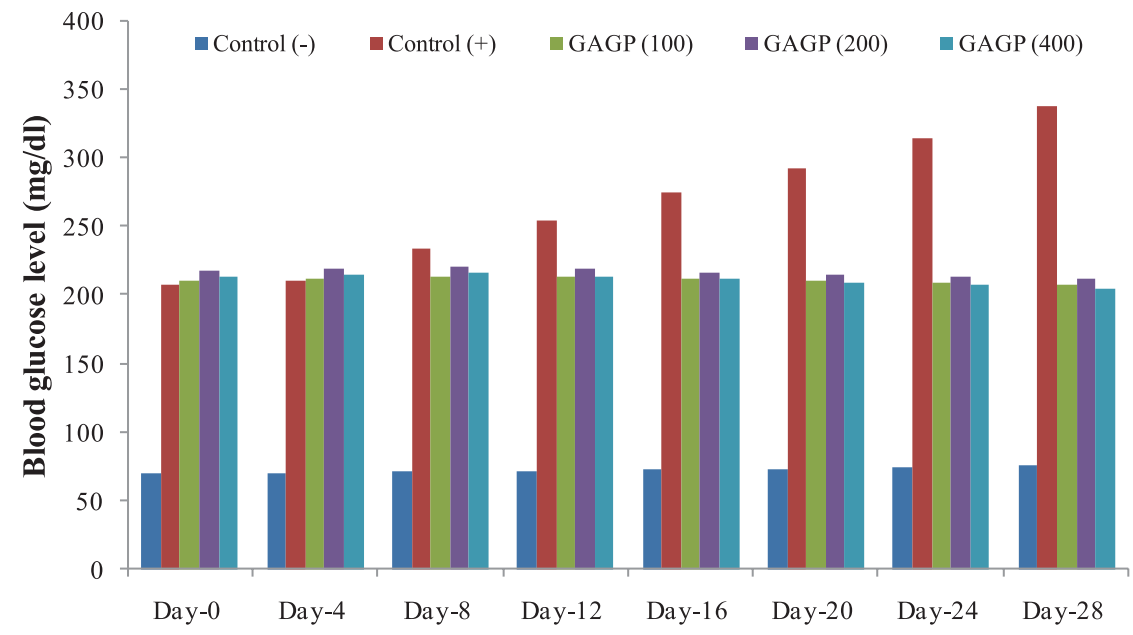

Blood glucose observation (day)

Figure 3. Effect of administration of GAGP on blood glucose level.

Table 2. Effect of administration of GAGP on blood serum profile.

\begin{tabular}{|c|c|c|c|c|c|c|c|}
\hline Group & $\begin{array}{c}\text { Triglyceride } \\
(\mathbf{m m o l} / \mathbf{l})\end{array}$ & $\begin{array}{c}\text { Cholesterol } \\
(\mathrm{mmol} / \mathrm{l})\end{array}$ & $\begin{array}{c}\text { HDL } \\
(\mathbf{m m o l} / \mathrm{l})\end{array}$ & $\begin{array}{c}\text { LDL } \\
(\mathrm{mmol} / \mathrm{l})\end{array}$ & $\begin{array}{c}\text { Creatinine } \\
(\mu \mathrm{mol} / \mathrm{l})\end{array}$ & $\begin{array}{c}\text { Urea } \\
(\mathrm{mmol} / \mathrm{l})\end{array}$ & $\begin{array}{c}\text { Alkaline phosphate } \\
(\mu / \mathrm{l})\end{array}$ \\
\hline Control (-) rats & $1.23 \pm 0.06^{\mathrm{a}}$ & $1.33 \pm 0.07^{\mathrm{a}}$ & $0.79 \pm 0.03^{b}$ & $0.07 \pm 0.01^{\mathrm{a}}$ & $21.8 \pm 1.66^{\mathrm{a}}$ & $4.78 \pm 0.17^{\mathrm{a}}$ & $341.6 \pm 21.20^{\mathrm{a}}$ \\
\hline Control $(+)$ rats & $1.68 \pm 0.20^{\mathrm{b}}$ & $1.48 \pm 0.06^{\mathrm{b}}$ & $0.58 \pm 0.04^{\mathrm{a}}$ & $0.16 \pm 0.05^{\mathrm{b}}$ & $30.0 \pm 1.14^{\mathrm{b}}$ & $7.44 \pm 0.24^{c}$ & $473.8 \pm 58.30^{\mathrm{b}}$ \\
\hline GAGP (100 mg) & $1.57 \pm 0.03^{\mathrm{a}}$ & $1.47 \pm 0.08^{\mathrm{a}}$ & $0.69 \pm 0.01^{\mathrm{ab}}$ & $0.14 \pm 0.08^{\mathrm{a}}$ & $28.26 \pm 1.09^{\mathrm{ab}}$ & $6.92 \pm 0.15^{\mathrm{bc}}$ & $441.8 \pm 24.41^{\mathrm{a}}$ \\
\hline GAGP (200 mg) & $1.47 \pm 0.08^{\mathrm{a}}$ & $1.42 \pm 0.05^{\mathrm{a}}$ & $0.70 \pm 0.04^{\mathrm{ab}}$ & $0.14 \pm 0.03^{\mathrm{a}}$ & $27.36 \pm 2.33^{\mathrm{ab}}$ & $6.78 \pm 0.44^{\mathrm{bc}}$ & $439.4 \pm 37.26^{\mathrm{a}}$ \\
\hline GAGP (400 mg) & $1.34 \pm 0.17^{\mathrm{a}}$ & $1.39 \pm 0.04^{\mathrm{a}}$ & $0.72 \pm 0.05^{\mathrm{ab}}$ & $0.12 \pm 0.02^{\mathrm{a}}$ & $26.66 \pm 1.47^{\mathrm{ab}}$ & $6.32 \pm 0.14^{b}$ & $405.7 \pm 21.17^{\mathrm{a}}$ \\
\hline
\end{tabular}

Each value is expressed as mean SD. The values in the column with different letter are significantly different $(\mathrm{p}<0.05)$.

However, there was a significant difference $(p<0.05)$ recorded in BW of treated diabetic groups at day-4 as compared with the diabetic control group. The diabetic groups treated with different concentrations of GAGP showed slight increment on $\mathrm{BW}$ throughout the experiment. The increase in BW of treated diabetic groups could be due to the preventive action of GAGP on the damage of cells due to severe breakdown of fats and metabolism of protein in the diabetic state.

\section{Blood glucose levels}

As shown in Figure 3, diabetic control group rats which were induced with alloxan showed significant difference $(p<$ 


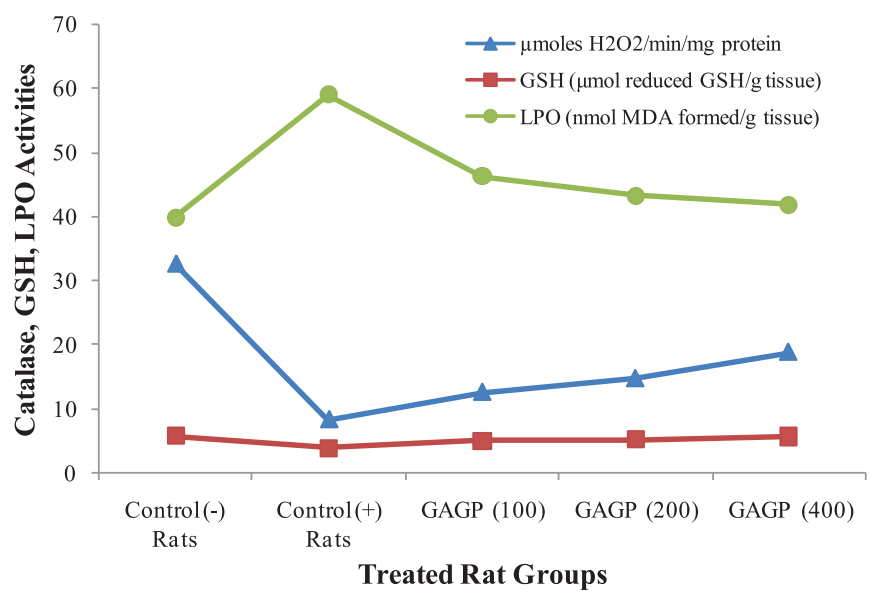

Figure 4. Effect of administration of GAGP on catalase activity, GSH, and LPO.

0.05) in blood glucose levels throughout the study as compared with the normal control group rats probably due to the rapid action of alloxan since it results in rapid depletion of beta cells by DNA alkylation and accumulation of cytotoxic free radicals. In the present study, three different dosages of GAGP at a concentration of 100,200 , and $400 \mathrm{mg} / \mathrm{kg}$ of BW showed a significant difference $(p<0.05)$ at day- 8 of treatment in blood glucose levels in alloxaninduced diabetic rats compared with diabetic control group. This may be due to the functional properties of GAGP as an antidiabetic agent. However, there is also a significant difference $(p<0.05)$ between the blood glucose levels of the GAGP treated diabetic rats as compared with the diabetic control group from day-12 to end of the study. In contrast, blood glucose levels of untreated diabetic rats remained elevated throughout the experiment.

\section{Blood serum profile}

As shown in Table 2, alloxan treatment will increase the chemical composition levels of serum such as alkaline phosphatase, urea, creatinine, low-density lipoprotein (LDL), cholesterol and decrease the high-density lipoprotein (HDL) level. But, treatment with the GAGP reversed the alloxan-induced changes. Serum of triglyceride, cholesterol, alkaline phosphatase, urea, HDL, LDL, and creatinine levels were significantly decreased $(p<0.05)$ as compared with the diabetic control group. Treatment with the GAGP improved the diabetes mellitus conditions as indicated by the parameters of serum profile.

\section{Catalase activity}

Catalase is one of an important enzyme in an antioxidant system that plays crucial scavenger enzyme which can be found in peroxisomes. Furthermore, catalase is a type of hemoprotein, which breaks down the harmful $\mathrm{H}_{2} \mathrm{O}_{2}$ into $\mathrm{O}_{2}$ and $\mathrm{H}_{2} \mathrm{O}$, which guards the tissue againt highly reactive hydroxyl radicals. In this investigation, catalase levels were found to decline as compared with the diabetic control group, this might be due to inhibition of the enzyme. In contrast, treatment with GAGP demonstrated improved enzymatic activity towards the normal in various dosages. Therefore, the result showed that GAGP has the ability to counter back the oxidative damage in alloxan-induced hyperglycemic rats with an increase in enzymatic activity; additionally, there is a significant difference $(p<0.05)$ present among all the groups as compared with normal control as shown in Figure 4.

\section{Reduced GSH}

Reduced GSH or commonly known as GSH is the smallest intracellular molecule with low molecular thiol antioxidant that is ubiquitous in a living environment. GSH occurs naturally in all type of cells and plays an important role in cell protection and acts as a crucial defense against free radicals. In this research work, the diabetic control group showed significantly reduced GSH level in pancreatic tissue compared with normal control group. On the other hand, administration of GAGP at various dosages to alloxaninduced diabetic rats showed significant improvement in GSH levels near to normal as compared with normal control and diabetic control; although there is a significant difference $(p<0.05)$ among the groups as presented in Figure 4.

\section{Lipid peroxidation (LPO)}

LPO can be defined as the oxidative deterioration of unsaturated fatty acids. LPO produces numerous products, which some of them are electrophiles (Oyedemi et al., 2010). One of the LPO substances which is commonly used as a biomarker for tissue damage is the reactive aldehyde, MDA. MDA is a by-product that generates naturally during the process of LPO. As shown in Figure 4, there was a significant difference $(p<$ 0.05 ) between the diabetic groups as compared with the normal control group. Tissue LPO in diabetic groups was increased as compared with control group because alloxan induces a high level of MDA in diabetic animals which might be due to high glucose stress in diabetes which promoted the production of reactive oxygen species that reacts with polyunsaturated fatty acids inside the cell membrane leading to increase in MDA level. In this study, significantly reduced LPO was recorded in the groups administered with the different dosages of GAGP that almost attained to normal level as compared with the untreated diabetic group.

\section{CONCLUSION}

Fungal culture $T$. viride has shown transglycosylation reaction through the activity of CGTase on M. oleifera polyphenol constituents to synthesize polyphenol glycosides. Analysis of ${ }^{1} \mathrm{H}$ and ${ }^{13} \mathrm{C}$ NMR of the isolated polyphenol glycosides established the chemical structures of GAGP, EAGP, and CGP. The GAGP was furthermore assayed for its anti-diabetic and antioxidant potential activities. The results show that in vivo treatment with GAGP reversed alloxan-induced diabetes. Serum triglyceride, cholesterol, alkaline phosphatase, urea, HDL, LDL, and creatinine levels were significantly decreased $(p<0.05)$ as compared with the diabetic control group. Additionally, GAGP showed significant improvement in GSH levels near to normal and significantly reduced LPO that is almost attained to normal level as compared with the untreated diabetic group.

\section{ACKNOWLEDGMENT}

This work was financially supported by UMS Research Grant 2015, under the Universiti Malaysia Sabah. We are also thankful to Institute for tropical biology and conservation, 
Universiti Malaysia Sabah, Kota Kinabalu, Malaysia for NMR Spectroscopy analysis services.

\section{CONFLICT OF INTEREST}

Nil.

\section{FINANCIAL SUPPORT}

None.

\section{REFERENCES}

Babu R, Chaudhuri M. Homewater treatment by direct filtration with natural coagulant. J Water Health, 2005; 3:27-30.

Charoensin S. Antioxidant and anticancer activities of Moringa oleifera leaves. J Med Plants Res, 2014; 8:318-25.

Cherbal A, Kebieche M, Yilmaz E, Aydoğmuş Z, Benzaouia L, Benguessoum M, Benkedidah M, Madani K. Antidiabetic and hypolipidemic activities of Algerian Pistachialentiscus L. leaves extract in alloxan-induced diabetic rats. S Afr J Bot, 2017; 108:157-62.

Chiang, HM, Lin YT, Hsiao PL, Su, YH, Tsao HT, Wen KC. Determination of marked components-aloin and aloe-emodin-in aloe vera before and after hydrolysis. J Food Drug Anal, 2012; 20(3), 646-52.

Dillard CJ, German JB. Phytochemicals: nutraceuticals and human health. J Sci Food Agr, 2000; 80:1744-46.

Ghasi S, Nwobodo E, Ofili JO. Hypocholesterolemic effects of crude extract of leaf of Moringa oleifera Lam in high-fat diet fed wistar rats. J Ethnopharmacol, 2000; 69:21-5.

Hashmi MI, Nazir SO, Sulistyo JO. Antimelanogenesis activity of polyphenol glycoside synthesized by transglycosylation reaction of CGTase from Xanthomonas campestris. IJRAFS, 2014; 2:1-8.

Kar A, Choudhary BK, Bandyopadhyay NG. Comparative evaluation of hypoglycemic activity of some Indian medicinal plants in alloxan diabetic rats. J Ethnopharmacol, 2003; 84:105-8.

Kasolo JN, Bimenya GS, Ojok L. Phytochemicals and uses of Moringa oleifera leaves in Ugandan rural communities. J Med Plants Res, 2010; 4:753-7.

Manickam D, Periyasamy L. Antidiabetic effect of methanolic extract of Decalepis hamiltonii root in normal and alloxan-induced diabetic rats. J Pharm Res, 2013; 6:166-72.

Mehta K, Balaraman R, Amin AH, Bafna PA, Gulati OD. Effect of fruits of Moringa oleifera on the lipid profile of normal and hypercholesterolemic rabbits. J Ethnopharmacol, 2003; 86:191-5.

Nayak B, Liu RH, Tang J. Effect of processing on phenolic antioxidants of fruits, vegetables, and grains - a review. Crit Rev Food Sci Nutr, 2015; 55:887-918; doi:10.1080/10408398.2011.654142.

Nazir S, Sulistyo J, Hashmi MI, Ho AL, Khan MS. Enzymatic synthesis of polyphenol glycosides catalyzed by transglycosylation reaction of cyclodextrin glucanotransferase derived from Trichoderma viride. J Food Sci Tech, 2018; 55:3026-34; doi:10.1007/s13197-018-3223-x

Oyedemi SO, Bradley G, Afolayan AJ. In vitro and vivo antioxidant activities of aqueous extract of Strychnoshenningsii Gilg. Afr J Pharm Pharmaco, 2010; 4:070-8.
Pari L, Latha M. Protective role of Scopariadulcis plant extract on brain antioxidant status and lipid peroxidation in STZ diabetic male Wistar rats. BMC Complement Altern Med, 2004; 4:1-8.

Satoh T, Miyataka H, Yamamoto K, Hirano T. Synthesis and physiological activity of novel tocopheryl glycosides. Chem Pharm Bull, $2001 ; 49: 948-53$.

Shimoda K, Hamada H. Enzymatic synthesis and antiallergic activities of curcumin oligosaccharides. Biochem Insigh, 2010, $3: 1-5$.

Shimoda K, Kondo Y, Abe K, Hamada H, Hamada H. Formation of water soluble vitamin derivatives from lipophilic vitamins by cultured plant cells. Tetrahedron Lett, 2006; 47:2695-8.

Siddhuraju P, Becker K. Antioxidant properties of various solvent extracts of total phenolic constituents from three different agroclimatic origins of drumstick tree (Moringa oleifera Lam.) leaves. J Agr Food Chem, $2003 ; 51: 2144-55$.

Sulistyo J, Dinoto A, Handayani R. Inhibitory activity of enzymatically synthesized polyphenol glucosides against melanogenesis and mutagenesis. BioSMART, 2001; 3:1-6.

Sulistyo J, Handayani R, Rahayu RD. Assay for transglycosylation reaction of Xanthomonas campestris on carbohydrate sources. Int $J$ Res Agr Food Sci , 2014; 2:1-7.

Prince PS, Stanely M, Kamalakkannan N, Menon VP. Antidiabetic and antihyperlipidaemic effect of alcoholic Syzigium cumini seeds in alloxan induced diabetic albino rats. J Ethnopharmacol, 2004; 91:209-13.

How to cite this article:

Nazir S, Sulistyo J. Functional properties of glycoside synthesized using polyphenolic extract of Moringa oleifera catalyzed through transglycosylation reaction. J Appl Pharm Sci, 2019; 9(05):058-064. 